\title{
Feminist Perceptions and the Challenges for Women's Education in Jeddah, Saudi Arabia in the 21st Century
}

\author{
Khadijah Bawazeer \\ Department of European Languages and Literatures \\ College of Arts and humanities, English Language Institute \\ King Abdulaziz University, Saudi Arabia \\ E-mail: kbawazeer@kau.edu.sa
}

Doi:10.7575/aiac.alls.v.6n.1p.189

Received: 04/10/2014

URL: http://dx.doi.org/10.7575/aiac.alls.v.6n.1p.189

Accepted: 18/12/2014

\begin{abstract}
This article aims to contribute to the ongoing discussion about women's education. Conflicting discourses, regarding the positions of women as student learners, create an educational challenge that faces the GCC countries in the $21^{\text {st }}$ century. This study explores the prevalent feminist positions in Jeddah in Saudi Arabia and presents the findings to the public and to decision makers in KSA. The data is generated in two ways: focus group and a questionnaire. Aside from the information they yield, the results of the focus group interviews were used to develop a questionnaire that was distributed among students from various departments at King Abdelaziz University women's main campus. The article finally discusses the results of this survey and also explores the debatable concepts of fairness vs. equality in the context of the findings.
\end{abstract}

Keywords: women, feminism, education, Jeddah, Saudi Arabia, feminist perception, pro-Islamic feminism, prowestern feminism.

\section{Introduction}

\subsection{Problem}

Conflicting discourses regarding the positions of women as learners are part of the educational challenges that face the Gulf countries (GCC) in the $21^{\text {st }}$ century. Each position generates a different educational scenario and demands a different educational strategy. This article aims to contribute to the ongoing discussion about women's education in Saudi Arabia (KSA hereafter), which is witnessing an active period of educational reform in all respects including the education of women (Abouchakra, Nabih, Moujaes, and Samman, 2008, p.3, 10, 20-21, 24-26, 28).

There are various positions regarding women in KSA. This article investigates some of the prevalent feminist positions and discourses in Jeddah, KSA, and the connected perceptions of the role and place of women in society. These positions have not been studied yet therefore there is very little first hand literature on them. I use Michael Foucault's perception of discourse in The Archeology of Knowledge (1972), as language formations that express and comprise a set of discursive ideas that are loaded with particular significations (p. 21-32). The article also attempts to explore how the women in the investigated samples perceive their rights and obligations in order to explore some of their specific educational needs and how these needs challenge education in different ways (Almunajjid, 1997, p. 1-9, 58-91).

This research is done in two parts: a qualitative examination through a focus group and a quantative questionnaire (Shah \& Corley, 2008 p: 1822-1824). I choose this research design because the focus group leads the researcher into what to ask about in the questionnaire. Moreover, I draw on the concepts of micro and macro analyses of Emile Durkheim (1858-1917) as presented in Sensation and Perception (Goldstein, 2010). By conducting a microanalysis, I attempt to arrive at some macro understanding of the problem at hand to help define the educational needs of regional women and the circulating perceptions of the concepts associated with the word 'feminism'.

I want to remind my reader at this junction that there is a scarcity of studies on women in KSA, which is needed at both overall frames and details. Therefore, this article attempts to formulate a framing picture of the local feminist scenario in regard to education in Jeddah, KSA. The information generated, though concerns Jeddah, can be useful to education decision-makers throughout KSA because the Ministry of Education in KSA uses the same books, curriculum, and systems throughout KSA. As such it can help deduce the specific educational needs of regional women in light of the circulating perceptions of the concepts associated with the word 'feminism' in this city.

\subsection{Research questions}

In the process, I explore the following questions: how did the participants understand equality between men and women as well as fairness in their relationships? Where from and how should local women derive their models of behavior and thought regarding their position as women? Are school readings of the history of prominent Muslim women's lives that suggest them as role models consistent with actual social patterns since girls are given these women as models in 
school? Or are traditional women and grand parents to be taken as life models, which are both more or less specific historical and cultural models. Another model given to girls is derived from what is presented on TV and what is being talked about currently in journals and newspapers. All these variables are bound by time, place and culture though at modern times, there is a crossing of space through Internet and TV that claims fluidity yet the interpretation of what a person sees on media or reads in journals remains culture specific. This prompts the question of to what extents are gender/feminist perceptions bound by time, place and culture (McCormick et al 1987) meaning are cultural condition are affected by time and place.

\subsection{Literature Review}

As I just said, there is a lack of research in the area of women's education and women's positions in KSA. However, there are some references on education and feminism that I checked. There are articles by Abeer Allem and Leigh Nolan respectively that summarize the KSA reforms. The two by Allem discuss reform in general. These are "Saudi Arabia Speeds up Education Reform"(2009) and "Saudi Education Reforms Face Resistance" (2011) in Gulf News by Abeer Allem. The reason I quote these articles although such newspapers are not academic journals, is that they vocalize some public and official opinions. The third, by Leigh Nolan, titled keeping the Kingdom: the politics of higher education reform in Saudi Arabia (2011) focuses on higher education.

Of the latest scholarship close to the area under investigation is the study by Elyas and Picard in 2013 where in they critiqued higher education policy in KSA. (Elyas, T. \& Picard, M.Y. 2013 pages 31-41). In 2012, the same writers discussed Saudis resistance to globalization of education in their article: teaching and moral tradition in Saudi Arabia: a paradigm of struggle or pathway towards Globalization (p. 1083-1086). In 2010, a report from the ministry of higher education describes the Challenges and achievements of women's education in KSA and in 2005, in an article in the International Education Journal titled women and education in Saudi Arabia: challenges and achievements, Amany Hamdan gives an overview of the education of women in Saudi Arabia (p. 142-64).

In her paper on gender equality and school reform (2007), Madeline Arnot argues that the relationship between the concepts of feminism and education is affected by gender (p. 207-226). In the same vein, we can safely say that education is gendered in Jeddah. The gendering occurs in three ways: school segregation throughout the school years; physical activity classes for boys that are offered throughout the years of their schooling but not to girls, and home management classes offered only to girls in middle schools: seventh, eighth and ninth grades. However, some changes that indicate an attempt to revolutionize education in ways that do not offend the society occurred in KSA recently (Elyas \& Picard, 2013, p. 31-41; Hamdan, 2013, p. 55-59). One example of such change is that physical and home management classes are opened up for debate but not segregation in schools (Baki, 2004, p. 1-15). Women were also limited in vocational choices in Jeddah. Some of what is presented in The 'Girl Question' in Education: Vocational Education for Young Women in the Progressive Era (Bernard-Powers, 2011).

While segregation is not open to change at the moment because it is deeply grounded in the social customs, its pros and cons are debatable especially in developed countries. K. Stanberry (2013) considers both pros and cons of single sex education. She presents both side of the argument without deciding on one while Wilcox and Kovner Kline, in their article in Urban Review in (2013), lean more towards school segregation though they do not say whether this should be done form the start or later on and at what age or school level should segregation occur. However, Kesler (2010) sees that gender segregation does not work in USA and that there is no science behind the claim that boys and girls are essentially different. Orfield, Frankberg \& Graces (2008) present similar ideas (Stanberry 2013; Wicox \& Kovner Kline 2013; Kesler 2010; Orfield, Frankenberg \& Garces, 2008).

Some other important concepts mentioned here and on which hinges the definition of different women positions in KSA are justice and fairness. Equality refers her to the equalization of women and men at all levels such as job pay, kinds of work done and expectations while fairness refers to a more socially and religiously inscribed concept of treating the other including women fairly. This necessitates equal job pay, which women in Saudi got since women jobs started but not necessarily the nature of jobs or expectations as per Muslim Doctrines that is discussed in details in Faith and Freedom: Women's Human Rights in the Muslim World (Afkhmi, 1995). Other relevant references are: Equity and equality in education (Roche, 2013); Managing Equality and Diversity (Kumra, Manfredi \& Vickers, 2012); and the book: A Theory of Justice (Rawls 1971).

\section{Method}

This research is an inductive empirical research (Emery \& Naseem 2010; Barber \& Stainton, 2009, p.47-53;) that aims to uncover the conflicting discourses regarding the positions of women as learners in Jeddah, Saudi Arabia, as part of the educational challenges that face the Gulf countries (GCC) in the $21^{\text {st }}$ century. Each position generates and demands a different educational scenario.

In this study I conduct a two-stage research, a preliminary qualitative study, in the form of a focus group, then a quantative one (Shah \& Corley, 2006, p. 1821-1835) in the form of a questionnaire. I employed the responses and analysis generated through the focus group in developing the questionnaire. However, I opted for this type of research because its qualitative aspects enabled me to explore the various feminist discourses while quantatively, the research produced data that yielded, albeit limited, accountable results.

This research methodology carries with it focus group and questionnaire classic limitations. For example, it does not take into consideration the variables that were not included in the questions and it takes experiences out of their context and presents them as numbers on a page. Some of these limitations are imposing certain directions on discussions and 
pronouncing some voices over others like that of active students over quiet ones, though the quiet ones may be as smart, or the voice of the teacher over that of her students. To avoid limitations of both methods, it is important to pay attention to process and details as much as possible. However, at this point, I am seeking some facts so even the semi qualitative focus group is employed to achieve those facts in the final analysis.

Furthermore, I attempt some macro assumptions on the bases of this study based on Emile Durkheim I draw concepts of micro and macro analyses of Emile Durkheim (1858-1917) to arrive at some macro understanding of the issue. I use the generated results as indications of a larger picture, since the same educational system is dispersed throughout KSA. As such, I employ the limited analysis I conduct to come up with a preliminary macro understanding of the issue. However the issues need further study and clarification.

\subsection{Focus group}

The focus group was conducted according to the perceptions of Stewart, Shamdasani \& Rook as presented in their 2006 book on focus groups (P. 8-13, 37-45, 54-59). The sample of the focus group consisted of eight students from my undergraduate translation class in their second or third university year from the women Sulaimania campus of King Abdelaziz University (KAU thereafter) in Jeddah, KSA. The participants were between 20-23 years old. All students in this group had finished a prep year at KAU. There were eight students in this class. All the eight students participated in both sessions. All the students in the first session showed up for the second session. The discussion was carried in English mainly. The focus group discussions were carried out in two sessions that took place in March 2013.

In the class previous to the first session, participants were told how important their participation is and that they have to be truthful in their responses. The students were asked to read about feminist discourses and to pay attention to women's attitudes in Jeddah, KSA. At the beginning of the first session, participants were retold how significant their participation may be and that they have to be truthful in their responses as well as at the beginning of the second session.

The prompts of the focus group were given to students before the sessions. They comprise three parts. Part one comprises prompts to stimulate participants' thinking over the topic of feminism. Part II is about the participants' perceptions of household, marriage and career. The first discussion investigated how feminism was defined, and how family and marriage, equality, education, equality in education, and jobs were perceived while part III discussed the Slaughter article and the following issues: equality and equality in education, and fairness.

At the end of discussion of day one, the students were asked to read the article, "Why Women Still Can't Have it All" by Ann Marie Slaughter (2012). In this article, Slaughter shifts form her previous stand that to the opposite opinion. She used to popularize the idea that women can have it all, but in this article she questions that and adapts her views.

The second session opened with a discussion of Slaughter's article, its feminist innuendos, Slaughter's shift of position, its reasons, and implications. Furthermore, the students had to reflect on the prompting questions and discuss them and discuss their understanding of the issues of equality, education equality and fairness. The data generated from the focus group comprised the base for the questionnaire.

\subsection{Focus Group prompts and questions}

Part I: prompts to stimulate participants' thinking over the topic of feminism given prior to the first session:

1. Do you think that there was more than one feminist school in Jeddah?

2. What do you think were the different feminist discourses in Jeddah?

3. To what position do you think you belong if there is more than one?

Part II: household, marriage and career

1. How many women \& men are members of your household?

2. Does your mother and/or father relate to your needs?

3. Do you face discrimination at home? In what way? By who?

4. Does your mother or father allow boys to focus on their studies?

5. Does your mother or father allow you to focus on your studies?

6. Does your mother or father act similarly towards girls/women and boys/men in the family?

7. Do you relate more to your mother or father? Why?

8. Is marriage important to you or your family and necessary to you?

9. Would you marry to please your family?

10. Do you think the rate of divorce is higher now than it was 50 years ago?

11. Do men in the Saudi society have to choose between marriage and career?

12. Do women have to choose between work and family?

13. Is there a difference between social public and private spheres? How?

14. Do you have role models? If so what are they?

Part III: in class, a discussion ensues regarding the article and the following issues: equality, fairness, and education

1. How do you understand equality?

2. How do you understand equal education? 
3. How do you define justice?

4. Do you think that perceptions of equality affect educational material?

5. Do you think that perceptions of equality affect educational behavior?

6. Does education fulfill your job needs? What are these needs?

7. Does education fulfill your social needs?

8. Does education fulfill your marital needs?

9. Do you think boys and girls should be segregated in school?

10. Why do you think boys and girls should be segregated in school?

11. Do you think women should teach young boy instead of men?

12. If yes and if no why?

13. Do you think young boys would experience a cultural shock when moved later to an all men school?

14. What do you think of the Slaughter article you read? What are your views on the matters presented in the article?

15. Would it cause tension in a family and lack of satisfaction?

16. Would it affect the relationship between husband and wife? How?

17. Have you worked in a job before?

18. Would you rather work in a segregated or in an unsegregated job environment and why?

19. What do you think are the feminist tendencies in Jeddah?

2.3 Questionnaire

2.2.1 The focus group discussions generated some perceptions and questions that were investigated further in the questionnaire, which provides frequency statistical data on which the perceptions of feminist discourses in Jeddah are established. One hundred and forty-three questionnaires were randomly distributed among female students in KAU in April 2013 of which I obtained 100 responses.

\subsubsection{Formulation of the questionnaire}

The questionnaire is composed of three parts. The first part questions age, education and income of the participants but no names are asked for. It indicates if any of these factors has something to do with the stand adopted by the participant. I found out that neither age nor education influenced women position but that a high level of affluence did. Affluent women were more for western style than average ones. The second part is formed of 24 questions that investigate attitudes to education, marriage, and finance. Part III comprises three open questions that indicate the My position of the respondents towards feminism and women's education, and where do Saudi women derive their feminist role models from.

Among other questions, the respondents were asked if education fulfills the personal and social needs of women? What does education prepare girls to do? How important is marriage to KSA women? Is it more important than education? Would women university students and graduates sacrifice a job for marriage? Do they expect their husbands to support them financially? What are their positions regarding feminism and education? Where from and how should women derive their models of feminism? Are readings of the history of role model women lives consistent with social practices? Finally, to what extent are feminist perceptions bound by time, place and culture?

2.3.2 The purpose of the questionnaire was to investigate the different perception of the participants of feminist discourses in Jeddah and to offer analysis that can help education decision makers to make applicable decisions.

\subsubsection{The questionnaire}

Please respond to the following questionnaire that aims at investigating the predominant feminist perceptions and the challenges for gender education Saudi Arabia. Your Privacy will be maintained.

Respondents' info: please circle the applicable.

\section{Age groups}

\section{Education}

a. Where did your school education take place?

1.In a government school

2.In a private school in Jeddah

3.In a private American or English school in Jeddah

4.Abroad (e.g. USA or UK)

\section{b. Are you currently?}

1. Studying for a BA

3. Studying for a PH.D

5. Teaching undergraduates

\section{Studying for a MA}

4. A schoolteacher

6. Teaching gradates 
Financial conditions

Which of these categories does the income of your family's monthly income falls into:
1. $5000 \mathrm{SR}$
2. 10000
3. 2000
4. 30000
5. 40000
6. 50000

II- Please check the statement that matches your opinion from the scale of 1-5: $(1=$ strongly agree; $2=$ agree; 3=inapplicable; $4=$ disagree; 5 = strongly disagree)

\begin{tabular}{|c|c|c|c|c|}
\hline 1. & Local education fulfills my needs. & 123 & 4 & 5 \\
\hline 2. & Education is a way for me to get a job. & 123 & 4 & 5 \\
\hline 3. & Education trains me for future jobs & 123 & & 5 \\
\hline 4. & Education does not train me for future jobs. & 123 & 4 & 5 \\
\hline 5. & Marriage is important for women in my culture. & 123 & & 5 \\
\hline 6. & Marriage is of primary importance in my culture. & 123 & & 5 \\
\hline 7. & Marriage is less important than money making in my culture. & 123 & & 5 \\
\hline 8. & I will sacrifice my job for my marriage. & 123 & 4 & 5 \\
\hline 9. & I will not sacrifice my job for my marriage. & 123 & 4 & 5 \\
\hline 10. & I expect my husband to support me. & 123 & 4 & 5 \\
\hline 11. & Working for pay enables me to be financially independent. & 123 & 4 & 5 \\
\hline 12. & The money I make will help pay basic expenses for my family. & 123 & & 5 \\
\hline 13. & I can buy luxuries with the money I make. & 123 & 4 & 5 \\
\hline 14. & I had a bad marriage experience. Thus, I want to focus on a career. & 123 & & 5 \\
\hline 15 . & $\begin{array}{l}\text { In my society, women follow western feminist perceptions concerning the position of } \\
\text { women. }\end{array}$ & 123 & & 5 \\
\hline 16. & $\begin{array}{l}\text { In my society, women do not follow western feminist perceptions concerning the } \\
\text { position of women. }\end{array}$ & 123 & & 5 \\
\hline 17. & $\begin{array}{l}\text { In my society, women adhere to traditional perceptions concerning the position of } \\
\text { womanhood }\end{array}$ & 123 & & 5 \\
\hline 18. & I like watching TV shows that present images of women in them & 123 & & 5 \\
\hline 19. & In my society, women follow traditional perceptions concerning the duty of women. & 123 & 4 & 5 \\
\hline 20. & My Grandmother is my role model & 123 & 4 & 5 \\
\hline 21. & Feminist perceptions are shaped by time, place and culture & 123 & 4 & 5 \\
\hline 22. & Feminist perceptions are shaped by time, place and culture? & 123 & 4 & 5 \\
\hline 23. & $\begin{array}{l}\text { The history of women's lives is consistent between current traditional perceptions } \\
\text { and idealized images of Muslim women and their roles in history? }\end{array}$ & 123 & & 5 \\
\hline 24. & Education is gendered in SA. & 123 & & 5 \\
\hline
\end{tabular}

Part III- Feel free to express your views here (write as much as you wish)

- Saudi women derive their feminist role models from

- My position regarding feminism in SA is

- My position regarding women's education in SA is

\section{Results}

\subsection{Results of the focus group}

Most participants (6 out of 8 ) would rather send their kids to an all ladies school and they think this is not just a postponement of the problems their young boys may face as they enter school but that entering school is a more than one fold process. Initially the young boys have to leave home and then they can deal with an all man environment. This group sees that Islam is not an outward show and that it demands a certain ethical behavior form both women and men, and that responsibility comes with the privileges, rights, respect, and liberty granted to women in Islam; some of which are still being struggled for by many women today. It also points out that traditions are not to be identical to religion and that they are to be respected as long as they do not conflict with the Islamic code, which is the primary point of reference. Most also thought that education fulfills their financial needs because they can find jobs with education but that this may reflect badly on their relationships with men. They also though that they must prioritize their interests and that in the final analysis kids and husbands are too important to sacrifice for the sake of material things. These ideas lead to the article by Slaughter that questions the validity and usefulness of classic oppositional feminism for women at large and questions if women can do it all, being professional at all fronts and taking care of the family. This brought around what the focus group participants thought of feminism and the positions of women in KSA, which took us to of the final conclusion of the three different positions presented above. 


\subsection{Results of the questionnaire}

The first part of the questionnaire indicates that age, education or affluence have something to do with the stand adopted by the participant. I found out that neither age nor education influenced women position and that a high level of affluence did. Affluent women were more for western style than average ones. In part two, the participants were asked to check the statement that matches their opinion from a scale of $1-5$ whereby $1=$ strongly agree; $2=$ agree; 3=inapplicable; $4=$ disagree; $5=$ strongly disagree.

Table 1 shows that the results of the questionnaire support the results of the focus group interviews. The participants' response to the question if education fulfills the personal and social needs of women in Jeddah was, 35.9 and 48.8 between agree and strongly agree. Most participants opted for marriage over making money. A majority of respondents thought marriage is very important. Almost $80 \%$ wanted their husbands to support them financially but $70 \%$ thought that working for pay enabled them "to be financially independent". $75 \%$ said they could use the money they make to fulfill some family needs while $40 \%$ thought it is a way for them to have luxuries. However, slightly more than $80 \%$ of the respondents wanted to keep their jobs in case their marriage does not work which indicates that the majority was hesitant to give up their financial independence at the onset of their marriage but they expected financial support from their husbands. Most respondents thought that their education does not prepare them for future careers nor does it prepare men, but that it was enough for women to get a job that is based on their academic average in the university, which ironically maintains equality in the negative. Most wanted to marry even if there is a possibility of divorce. However, some were apprehensive about marriage. Most preferred that their man worked outside the home while they raised the family. $\% 50$ of the respondents thought most women did not adhere to contemporary feminist trends. A much lesser number of respondents $(25 \%)$ thought that their social circles followed the perceptions of mainstream western feminism concerning the position of women. When questioned about women following traditional perceptions concerning the duty of women $50 \%$ thought that women did, $13 \%$ do not have an opinion regarding this while $37 \%$ thought that women did not adhere to tradition. A majority that that times and social conditions affect feminist perceptions (79\%) while 50\% was not sure if The history of women's lives maintains consistency in representation.

Table 1. responses to the questionnaire

\begin{tabular}{|c|c|c|c|c|c|}
\hline \multirow[t]{2}{*}{ No of Question } & \multicolumn{4}{|c|}{ Responses in \% } & \\
\hline & 1 & 2 & 3 & 4 & 5 \\
\hline 1. & 34.9 & 40 & 0 & 13.1 & 12 \\
\hline 2. & 54 & 34.5 & 0 & 14 & 10.5 \\
\hline 3. & 20 & 24.8 & 29.2 & 16 & 10 \\
\hline 4. & 20 & 25 & 30 & 15 & 10 \\
\hline 5. & 60 & 20 & 5 & 7 & 8 \\
\hline 6. & 60 & 20 & 5 & 7 & 8 \\
\hline 7. & 15 & 20 & 20 & 25 & 20 \\
\hline 8. & 49.5 & 19.5 & 4 & 7 & 10 \\
\hline 9. & 6 & 10 & 4 & 20 & 50 \\
\hline 10. & 39.85 & 39.32 & 9.78 & 5.35 & 5.7 \\
\hline 11. & 35 & 40 & 9 & 8.78 & 7.22 \\
\hline 12. & 31.8 & 43.3 & 13.6 & 6.7 & 5 \\
\hline 13. & 22.3 & 17.8 & 15.6 & 24.2 & 20.1 \\
\hline 14. & 6.4 & 40.6 & 7 & 40 & 6 \\
\hline 15. & 15.9 & 9.2 & 14 & 50 & 15.9 \\
\hline 16. & 29.9 & 31.1 & 29 & 7.8 & 29.9 \\
\hline 17. & 25.8 & 24.3 & 31.3 & 9.7 & 8.9 \\
\hline 18. & 16.5 & 20.5 & 30 & 13.5 & 19.5 \\
\hline 19. & 19.5 & 30.5 & 13 & 21 & 16 \\
\hline 20 . & 7.1 & 7.9 & 5.1 & 49.9 & 34 \\
\hline 21. & 33 & 46 & 3.5 & 8 & 7.1 \\
\hline 22. & 33.7 & 44.9 & 2.4 & 10 & 9 \\
\hline 23. & 15 & 16 & 50 & 10 & 9 \\
\hline 24. & 20.4 & 24.3 & 30 & 13.3 & 10 \\
\hline
\end{tabular}

The last part of the questionnaire asks respondents to reply to three points that identify where Saudi women draw their role models as well as the position of the respondents regarding feminism and education in KSA. Some respondents to the point of "where from do Saudi women derive their feminist role models" said women derive their models from media, some from history, recent or remote, while some indicated that they "do not know". The second response in part III of the questionnaire showed that the three positions, as described earlier emerged again. They are one that emulates western women; a second that is pseudo religious, and a third, in between group that is both contemporary and Islamist at the same time. As far as the last point is concerned, the last group, forming a statistical majority, agrees with most of the current educational practices and purposes. The participants, in this position, thought 
that women's conditions are generally worse at the job front than in schools and that they may loose some of their privileges if they become the biggest or even an equal family provider. Some students from the third group demanded sport classes in school and some thought that home management classes are useless.

\subsection{General results}

Three positions emerge as the main discourses emerged as the main position in Jeddah, KSA in the Jeddah:

- The first is a small but highly educated and vocal group. The allegiances of this group might be questionable but there is no hard data to substantiate such assumption. Women in this position tend to glorify the conditions of white western feminism. Women in this group usually belong to the upper social strata.

- The second tends to focus on Islamic rituals. Women in this group oppose the perceptions of the first position and mixes tradition with religion in ways that confuse their boundaries. This group seems to be more from the lower social strata and they ally with it.

- The third is a group of women who think of themselves as contemporary and Islamist at the same time. They tend to affiliate with the second group despite their disagreement on some major issues. Both have reservations regarding the first group and both incorporate different layers of the society but this one is composed of the more affluent educated young people.

Furthermore, this group thinks that emulating western women cannot solve the educational problems for women in Jeddah since western societies went through different phases that responded to the socio-historical, political and economic conditions, which prevailed at certain historical moments. It also rejects the mimicking of male social conditions and demands changes that offer choices to women without imposing certain perceptions or behavioral patterns on them.

A majority of responses both in the focus group and in the questionnaire indicate a quest for fairness rather than equality both in official and domestic spheres.

\section{Discussion}

The first and the second positions above are usually called the pro-western and Islamist groups respectively. The two groups are oppositional and they contest the role of women and the concepts of equality and fairness. These two groups are highly vocal but most of the ladies did not feel that either group represented them and rejected both; the first on the grounds that it mimics foreign phenomena without considering cultural or historical difference and specifity, and the second because it does not take historical variables into account

The first two discourses are: the pro-white western women feminists and the Islamic traditionalists. The first group stresses equalization as a primary factor in addressing women's problems (Roche, 2013, p.1-4), and mimics white western women's feminist agenda, which might or might not cohere with the needs and concerns of local women. However, the responses indicate that this group is limited to a small number of elites, it fails to offer a clear differentiation between the various stages or waves of feminist movements went through in the west (Hewitt 2010, p.114; Acker, 1897, p. 419-420)

However, some contemporary feminists refute the validity of such feminist perceptions that require women to focus on their careers (Roche, 2013, p. 1-4), which ultimately necessitates either that women do not get married, may not have children, leave marriage and child bearing till late, leave child raising to others, or impose an incredible stress on women when they are requested to give their best at the job and home fronts. All seem rather limiting than liberating. (Slaughter, 2012)

Ann Mary Slaughter in her article in the Atlantic, "Why women still can't have it all" represents the fourth wave of white western feminism. She shifted her feminist position and raised the question of who pays the price for a woman's professional success and how fulfilling a job can be without a family, and by questioning the accuracy that women excel both at a professional and domestic fronts (Slaughter, 2012). She represents some powerful elitist white western women feminists who question the extent of possible liberation and how bound are feminist perceptions by time, place and culture (McCormick et. al 1987, p. 1-30). In other words, she reached her final conclusions because of certain personal experiences that she was in within a certain time, place, and culture.

The second group or the pro-Islamist group represents dogmatically religious women who strongly believe in Islam yet they tend, sometimes, to fuse religion with traditions without clearly delineating their boundaries. To this group, women are pure and beautiful if in a shell. An implied yet widely understood reference is that the shell is their protection so if they are out, they will be smudged, abused and exchanged between hands. Pro-Islamists argue that women should demand justice and fair treatment rather than equality since women and men are not exactly the same.

A main problem with the Islamist is that they tend to inscribe their agendas in past history without directly acknowledging and addressing the problems of contemporary women or the needs that stem form them including educational needs. Therefore, their discourse becomes overpowered and deactivated. Literature did not target this aspect directly so I rely for my analysis on the focus group and questionnaire results.

The above-mentioned two groups are highly vocal, tend to go to extremes and occupy most of the local written scene in media. They adopt oppositional points of view regarding the dispute of equalization vs. fairness but both groups tend to overlook the specifity of the social conditions by not taking the geographic and the historical conditions or both into serious consideration (Bernard-Powers 2010; Kesler 2010; Orfield, Frankenberg \& Garces, Wilcox \& Kovner Kline, 2013). This creates perceptual discrepancies, which risk the production of educational strategies that are not internally 
or externally coherent and that do not fulfill the current educational requirements. (Hemmings, 2001, p. 3-7).

As mentioned earlier, this research attempts to investigate the relationships between contemporary conditions and concerns of the Saudi women of Jeddah and the challenges this incurs on education in the $21^{\text {st }}$ century. The three positions identified in this research are either directly or indirectly oppositional. One contested spot is the challenge of equality and fairness. A majority of responses both in the focus group and in the questionnaire indicate a quest for fairness rather than equality both in official and domestic spheres.

Most participants of the focus group and most respondents of the questionnaire opted for the third position and disapproved of the two other positions. The first is rejected on the grounds that it mimics foreign phenomena without taking cultural or historical difference and specifity into consideration. The second disapproved of because it did not take historical variables into consideration, applied a very strict interpretation of Islamic code, and implicated tradition with religion in ways that did not clearly demarcate them from each other, and because of its prioritization system that may, for example, put covering before backbiting when the Quran specifically prohibits the second while it does not specify the method of covering.

The issues of fairness and equality are at the center of debates between the different positions and the groups that represent them. White western feminism, especially in its earliest waves based its struggles around the issue of equality. In fact the first wave of feminism was a quest of equality, especially equal pay and the right to vote (Roche, 2013, p.14). However, some contemporary fourth wave feminists tend to refute the validity of previous feminist perceptions. In the fourth feminist wave, white western women questioned, at times, if women can have it all and they raise the questions of who pays the price and how fulfilling a job can be without a family (Slaughter 2012), and wither feminism express the elites or all women (Arnot: p. 207-226; Hamdan: 47-53). The Islamists group objects to the concept of equality because they consider it unrealistic while they denote that the Quran indicates the necessity of dividing labor fairly rather than equally. The third group perceives this as a quibble over terms and thinks that we need to look at what ultimately can be achieved.

Each of three major players in the feminist scene imposes a different requirement on the educational system. The prowestern group demands a full emulation of western feminism, non-segregated schools, equal employment and identical educational programs for girls and boys; the pro-Islamist demand an educational model that is focused on raising a family at home; the third position demands freedom of choice with an Islamic model derived from the Quran and Hadith Sahih and that acknowledges the existing realities.

A majority of women in Jeddah prefer to have the rights prescribed for them in the Quran rather than have situations in which they loose their privileges and copy the struggles of western women. In this regard, AlMunajjed (1997) argues that the Quran gave women equal rather than identical rights with men at more than one level: personal, social, civil and political, and that it required similar duties and obligations such as praying, zakat or Hajj and promised similar rewards to both men and women but it does not sanction the mixing of the sexes (AlMunajjid, 1997, p. 67-83). Women adopting the third position maintain that they must re-inscribe their Islamic rights and acknowledge both diversity and cultural specifity. Sen and Grown, maintain in 1987 that feminism is not monolithic but rather it:

constitutes the political expression of the concerns and interests of women from different regions, classes, nationalities, and ethnic backgrounds. ... There is and must be a diversity of feminisms, responsive to the different needs and concerns of women, and defined by them for themselves (p. 18-19)

Based on this perception, they call for variations in the definition and functions of feminism on the basis of cultural and historical specifity. This holds true for women in Jeddah and by extension in KSA whose history is full of inspiring feminist models. In other words, the variant historical and cultural conditions result in variant

\section{Conclusion}

In summary, the research identifies three positions of women rights' advocates in Jeddah: the pro-western feminists who demand a complete abolition of segregation and a full integration of women into the western style feminism without considering the social consequences of their demands; the pro-Islamists who try to hold on to patterns that are somewhat obsolete, and a third position that acknowledges problems and is willing to consider both previous positions but it believes in indigenous solutions, rejects traditions when they contradict with Islam, and takes the social impact of their demands into consideration.

This research uses an investigation that works in the opposite direction of education strategists top down approach as it more or less investigates people at the lower managerial strata who do not make the decisions but get affected by them. In other words, it gives voice to the unvoiced.

Local women need to define their concerns clearly and focus on issues that are important to them such as their views of the issues of equality and fairness and investigate how equality is perceived and how it can be demanded within a framework of contemporary requirements and conditions. They must examine the current conditions operating on the ground, study how meanings shift at different historical moments. They should study how subcultures affect perceptions of the position, role and education of women, examine whether people are written-on by education or are freed by it.

Understanding these issues is important to setting up workable educational strategies at the end-user level. Educational strategists in KSA tend to use primarily a top down approach (Palmer, Rosch, \& Chase, p. 135-151). However, such an approach without investigation of the end-user reactions may face strong resistance. Decision makers must take the local conditions and all stakeholders into serious consideration when devising educational strategies and school 
curriculums. Therefore, in order to obtain relevant information regarding educational policies and in order to set clear and appropriate educational strategies that fulfill the needs and aspirations of Jeddah's women, we must examine how different positions propose a different set of challenges to the educational system, and analyze the current conditions operating on the ground. Being aware of these issues and incorporating them in educational strategies is of paramount important in order to come up with functional and sustainable educational plans that address the $21^{\text {st }}$ century challenges

There are two main limitations to this study. The first is that this study investigates women' perceptions only. However, it is pertinent to rerecord the positions and reactions of men since they are decision makers, in Jeddah, even when it comes to women (Gardiner, 2002). The second has to do with the scope of the study. This article does not attempt to present major conclusions because in order to offer justifiable wide scale conclusions, similar studies must be conducted in different parts of SA and the results of these studies has to be incorporated into a final analysis. The scope of the current study does not allow for such wide scale analyses.

However, further studies need to be conducted that delve deeply into single issues and positions in order to have a clearer and more conclusive picture of the situation of how feminism is perceived in KSA and on the situation of women there. Alternatively or at the same time the study needs to be expanded to give us a broader and more comprehensive picture of this issue. This study will hopefully spark more detailed examinations of its results and issues pertaining to it and it can help education decision makers to make more informed decisions specifically when it comes to setting material and curriculum for English and how women are represented in English books as well as women education in general.

\section{References}

Abouchakra, R., Nabih, M.,Moujaes, C.N. ,\& Samman, H.( 2008, March). How to succeed at education reform: the case for Saudi Arabia and the broader GCC region. Web retrieved 25 October 2013from: http:/www.booz.com/global/home/what-we-think/reports-white-papers/article-display/succeed-education-reform-casesaudi.

Acker, S. (1987). Feminist theory and the study of gender and education. International Review of Education, 33 (4): 419- 437.

Afkhami, M. (1995). Faith and Freedom: Women's Human Rights in the Muslim World. New York: Syracuse UP.

Allam, Abeer (2011, April 25). Saudi education reforms face resistance. Web retrieved in 25 October 2013 from: http://www.ft.com/cms/s/0/07607fb0-6f5d-11e0-952c-00144feabdc0.html\#axzz2j7DIYmpx

Saudi Arabia speeds up education reform (2009, April 15) Retrieved in 25 October 2013 from: http://gulfnews.com/news/gulf/saudi-arabia/saudi-arabia-speeds-up-education-reform-1.64121

AlMunajjed, M. (1997). Women in Saudi Arabia Today. London: Macmillan.

Arnot, M. (2007). Education Feminism, Gender Equality and School Reform in Late Twentieth Century England. International Studies in Educational Inequality, Theory and Policy, 3: 207-226.

Baki, R. (2004, June). Gender-segregated education in Saudi Arabia: its impact on social norms and the Saudi labor market. Education Policy Analysis Archives, 12(28): 1-15. Web retrieved 10 April 2013

Bernard-Powers, J. (2011). The 'Girl Question' in Education: Vocational Education for Young Women in the Progressive Era. London: Routledge

Elyas, T. \& Picard, M.Y. (2013). Critiquing of higher education policy in Saudi Arabia: towards a new neoliberalism. Education, Business and Society: Cotemporary Middle Eastern Issues, 6(1): 31-41.

Elyas, T. \& Picard, M. (2012). Teaching and moral tradition in Saudi Arabia: a paradigm of struggle or pathway towards Globalization?" Procedia - Social and Behavioral Sciences, 2012; 47:1083-1086.

Emery J. \& Naseem A. (2010). Scientism and Education: Empirical Research and Neoliberal Ideology. New York: Springer. Web retrieved on 26 October from:

http://books.google.com.sa/books?id=f5gveeSYcNQC\&pg=PA11\&dQ=deductive+empirical+research+in+in+educatio n\&source $=$ bl\&ots $=$ AlkCCNnK_m\&sig $=$ c9y3wtOTzrG43Lvbp2igf6JHCmc\&hl=en\&sa=Xei=8KxwUpuZEuyp0AW81 YBg\&redir_esc $=\mathrm{y} \# \mathrm{v}=$ onepage $\& \mathrm{q}=$ deductive $\% 20$ empirical\%20research $20 \%$ in $\% 20$ education\&f $=$ false

Foucault, M. (1972). The Archeology of Knowledge. (A. M. Sheridan Smith, Trans.). London: Routledge.

Gardiner, J.K. (2002). Introduction. In Gardiner, J. K. (Ed.), Masculinity studies and Feminist Theory (pp. 1 -30). New York: Columbia UP

Goldstein, E.B. (2010). Sensation and Perception. USA: Wadsworth.

Hamdan, A. (2005). Women and education in Saudi Arabia: Challenges and achievements. International Education Journal, 6(1): 42-64. Web retrieved 10 April 2013.

Hemmings, C. 2001. Why Stories Matter: The Political Grammar of Feminist Theory. Durham NC: Duke UP.

Hewitt, N. (2010). Introduction. In: Hewitt, N. (Ed.), No Permanent Waves: Recasting Histories of U.S. Feminism. 114. New Jersey: Rutgers UP. 
Kumra, S., Manfredi, S. \& Vickers, L. (2012) Managing Equality and Diversity: Theory and Practice. Oxford: Oxford UP.

Kesler, J. (2010). Gender segregating public schools does not work. http://thehathorlegacy.com Web retrieved 9 April 2013.

McCormick, K., Waller, G., \& Flower, L. (1987). Reading Texts: Reading, Responding, Writing. Boston: D. C. Heath \& Company Publishers.

Ministry of Higher Education. (2010).Women in Higher education: Saudi initiatives \& achievements. Saudi Arabia: Riyadh. Web retrieved 24 July 2013. From: http://www.mohe.gov.sa/

Nolan, L.E. (2012, March 16). Keeping the kingdom: the politics of higher education reform in Saudi Arabia. A paper presented at the annual meeting of the international Studies Association Annual Conference "Global Governance: Political Authority in Transition. Web retrieved 16 October 2103 from: http://citation.allacademic.com/meta/p500893_index.html

Rawls, J. (1971). A Theory of Justice. Cambridge, MA: The Belknap Press of Harvard UP.

Roche, S. (2013). Equity and equality in education. International Review of Education, 58(1): 1-4. Web 30 April 2013.

Sen, G. \& Grown, C. (1987). Development, Crises and Alternative Visions: Third World Women's Perspectives. New York: Monthly Review Press.

Shah, S.K., Corley, K.G. (2006). Building a better theory by bridging the quantative-qualitative divide. Journal of Management Studies 43 (8): 1821-1835

Slaughter, A. M. (July-August 2012) Why women still can't have it all. The Atlantic. Web retrieved 3 April 2013 from: http://www.theatlantic.com/magazine/archive/2012/07/why-women-still-cant-have-it-all/309020/

Stanberry K. (March 2012). Single-sex education: the pros and cons. Web retrieved 25 April 2013 from: http://www.greatschools.org/find-a-school/defining-your-ideal/1139-single-sex-education-the-pros-and-cons.gs?

Stewart, D.W., Shamdasani, P.N. \& Rook, D. (2006). Focus Groups, Theory and Practice, London: sage publications.

Wilcox, B.W. \& Kovner, K. K. (2013). Introduction. In B.W. Wilcox, B.W., Kl. K. Kovner (Eds.), Gender and Parenthood: Biological and Social Scientific Perspectives, 1-20. New York: Columbia UP. 